\title{
Emerging Trends in Chemistry and Pharmacology of $\beta$-Lactams
}

\section{Girija S Singh*}

Professor, Department of Chemistry, University of Botswana, Botswana

\section{Editorial}

The four-membered cyclic amides commonly known as 2 -azetidinones or $\beta$-lactams occupy a prominent place in the realm of organic and medicinal chemistry since the structure elucidation of penicillin showed the presence of $\beta$-lactam ring in it and the antibacterial activity of penicillin was attributed to the presence of $\beta$-lactam ring. The early investigations in organic chemistry were focused on development of synthetic methodologies because of delicacies involved in construction of four-membered strained ring whereas the researches in medicinal chemistry focused on broadening the spectrum of antibacterial activity. These studies led to development of several novel methodologies for construction of the $\beta$-lactam ring and discovery of several $\beta$-lactam antibiotics such as monobactams, cephalosporins, carbapenams, trinems, etc [1-4]. With the advent of stereochemistry and knowledge of its significance in determining the bioactivity, synthetic efforts concentrated on development of stereoselective methodologies - both diastereo- and enantioselective. The development of resistance in pathogens against this important class of antibiotics and the curiosity among pharmaceutical chemists to explore other biological properties of -lactams led to investigations in its alternative applications in medicinal chemistry which resulted into the discovery of novel $\beta$-lactams such as clavulanic acid, a $\beta$-lactamase inhibitor, and ezetimibe, a cholesterol absorption inhibitor. The $\beta$-lactams, to date, have been reported as inhibitors of several enzymes and anticancer agents as well.

Alongside the developments in synthesis and pharmaceutical applications of this class of compounds, their chemistry grew steadily. The degradation of the 2 -azetidinone rings forming $\beta$-amino acids and other products under acidic, basic, and photochemical conditions were documented long back which encouraged both synthetic and medicinal organic chemists to explore the potential of simple monocyclic $\beta$-lactams as synthons. The synthetic utility of $\beta$-lactam ring lies in ring-strain associated with it which makes the four-membered ring prone to cleavage on treatment with various types of reagents. The selective cleavage of the carbon-carbon or carbon-nitrogen bonds coupled with other transformations offer routes to structurally diverse

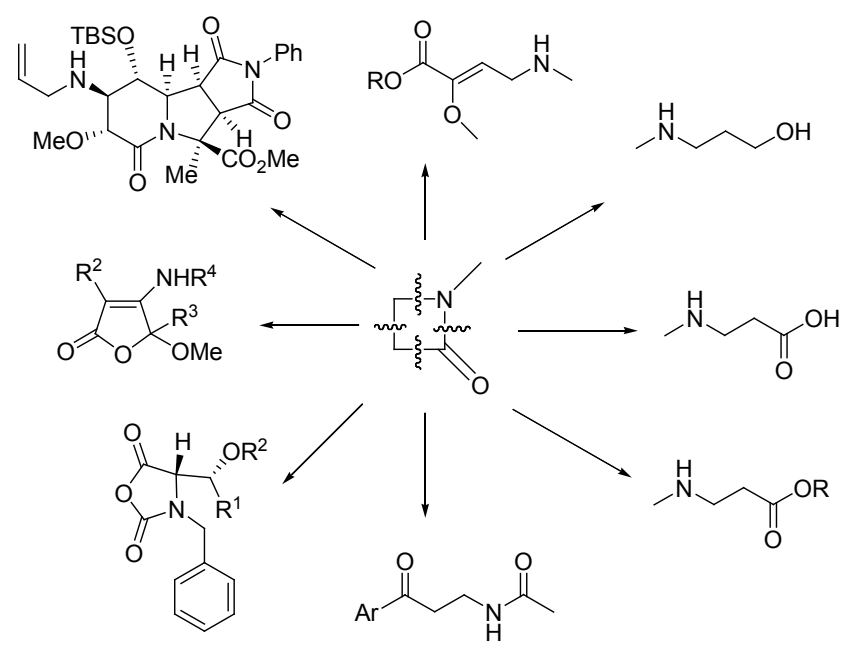

Figure 1: Synthetic applications of $\beta$-Lactams. types of molecules (Figure 1) many of which are of biological relevance. These include ring-opened products such as $\beta$-amino acids, $\beta$-amino esters and $\gamma$-amino alcohols, and heterocyclic compounds ranging from the smallest possible three-membered heterocycle aziridines to macrocyclic products. The application of simple $\beta$-lactams as synthons for diverse types of organic molecules has emerged as a potential tool in the arsenal of synthetic methods [5-7]. The studies are in progress to design and develop $\beta$-lactams with broader antibacterial activity with least side-effects. Efforts are on to explore its other biological properties such as anticancer, antitubercular, hypoglycemic, antimalarial, etc.

\section{References}

1. Singh GS, D'hooghe M, De Kimpe N (2011) Synthesis and reactivity of spirofused $\beta$-lactams. Tetrahedron 67: 1989-2012.

2. Singh GS (2003) Recent progress in the synthesis and chemistry of azetidinones. Tetrahedron 59: 7631-7649.

3. Singh GS (2004) Beta-lactams in the new millennium. Part-II: cephems, oxacephems, penams and sulbactam. Mini Rev Med Chem 4: 93-109.

4. Singh GS (2004) Beta-lactams in the new millennium. Part-l: monobactams and carbapenems. Mini Rev Med Chem 4: 69-92.

5. Deshmukh AR, Bhawal BM, Krishnaswamy D, Govande VV, Shinkre BA, et al. (2004) Azetidin-2-ones, synthon for biologically important compounds. Curr Med Chem 11: 1889-1920.

6. Alcaide B, Almendros P (2004) Beta-lactams as versatile synthetic intermediates for the preparation of heterocycles of biological interest. Curr Med Chem 11: 1921-1949.

7. Alcaide B, Almendros P, Aragoncillo C (2007) Beta-lactams: versatile building blocks for the stereoselective synthesis of non-beta-lactam products. Chem Rev 107: 4437-4492.
*Corresponding author: Girija S Singh, Chemistry Department, University of Botswana, Private Bag: 0022, Gaborone, Botswana, E-mail: singhgs@mopipi.ub.bw

Received March 26, 2013; Accepted May 02, 2013; Published May 06, 2013

Citation: Singh GS (2013) Emerging Trends in Chemistry and Pharmacology of $\beta$-Lactams . Mod Chem appl 1: e108. doi:10.4172/2329-6798.1000e108

Copyright: (c) 2013 Singh GS. This is an open-access article distributed under the terms of the Creative Commons Attribution License, which permits unrestricted use, distribution, and reproduction in any medium, provided the original author and source are credited. 